\title{
Family history of cardiovascular disease and non-HDL cholesterol in prepubescent non-obese children
}

\author{
Maria Wany Louzada Strufaldi ${ }^{1 *}$, Fabíola Isabel Suano de Souza ${ }^{1,2}$, Rosana Fiorin Puccinl ${ }^{3}$, Maria do Carmo Pinho Franco ${ }^{4}$ \\ ${ }^{1}$ PhD - Adjunct Professor, Department of Pediatrics, Escola Paulista de Medicina, Universidade Federal de São Paulo (Unifesp), São Paulo, SP, Brazil \\ ${ }^{2}$ PhD - Professor, Department of Pediatrics, Faculdade de Medicina do ABC (FMABC), Santo André, SP, Brazil \\ ${ }^{3}$ PhD - Full Professor, Department of Pediatrics, Escola Paulista de Medicina, Unifesp, São Paulo, SP, Brazil \\ ${ }^{4}$ PhD - Adjunct Professor, Department of Physiology, Escola Paulista de Medicina, Unifesp, São Paulo, SP, Brazil
}

Study conducted at Departamento de Pediatria, Escola Paulista de Medicina, Universidade Federal de São Paulo

(Unifesp), São Paulo, SP, Brazil

Article received: $1 / 12 / 2015$ Accepted for publication: 6/21/2015 *Correspondence: Address: Rua Botucatu, 598 São Paulo, SP - Brazil

Postal code: 04023-062 Phone: +55115576 4857 mwany@uol.com.br

Financial support: This study was funded by São Paulo State Research Foundation

(Fapesp). Project number 08/58963-0 (MWLS) and 07/58044-2 (MCPF).

\section{SUMMARY}

Objective: To describe the values of non-HDL cholesterol (NHDL-c) and the frequency of a family history of early cardiovascular disease (family HCVD) in healthy prepubescent children. Analyze the association between NHDL-c and family HCVD, and possible associations with other risk factors for cardiovascular disease (CVD).

Method: Cross-sectional study including 269 prepubescent (aged 6-10 years) schoolchildren with a normal body mass index (+1SD<BMI $>-2 \mathrm{SD})$. Data collected: Family HCVD; weight and height, waist circumference and systemic blood pressure; lipid profile (total cholesterol TC, HDL-c, triglycerides and LDL-c), NHDL-c calculation (CT-HDL-c, cut-off $=145 \mathrm{mg} / \mathrm{dL}$ ) and insulin resistance (HOMA-IR).

Results: High levels were found for NHDL-c in 10 (3.7\%) of these schoolchildren, and family early HCVD was found in 46 (17.1\%) of them. There was a weak association between family HCVD and NHDL-c (Cramer's-V-test $=0.120 ; \mathrm{p}=0.050)$. Among the children with NHDL-c $\geq 145 \mathrm{mg} / \mathrm{dL}, 4$ (40\%) have family HCVD. The presence of family HCVD was not associated with the variables being studied. The variables independently associated with NHDL-c $\geq 145 \mathrm{mg} / \mathrm{dL}$ were: HOMAIR (OR=1.7; 95CI 1.1-2.6) and diastolic blood pressure (OR=1.1; 95CI 1.02-1.2). Conclusion: NHDL-c values were associated with blood pressure and insulin resistance. Family HCVD was not associated with other classic risk factors for CVD, even though the frequency found was five times higher than that of high NHDL-c.

Keywords: dyslipidemias, cardiovascular diseases, child, primary prevention.

\section{INTRODUCTION}

Cardiovascular diseases (CVD) are the leading cause of mortality in adults worldwide. ${ }^{1}$ In Brazil, they also stand out as the leading cause of death, with rates of $28.8 \%$ and $36.9 \%$ for men and women, respectively. ${ }^{2}$

Atherosclerosis begins in childhood and progresses during adolescence and adulthood, and early identification is a crucial step toward reducing the morbidity and mortality related to it. The study by Bogalusa confirmed this finding when evaluating the autopsies of 204 healthy children and young adults between 2 and 39 years of age, who died due to trauma, and described the presence of fatty plaques in the aorta and coronary arteries in $50 \%$ of individuals aged between 2 and 15 years. ${ }^{3}$ The authors also noted that the greater the number of classic risk factors (obesity, dyslipidemia, diabetes mellitus, hypertension, and smoking) for CVD present, the greater the frequency and extent of the lesions. ${ }^{3,4}$

According to the American Academy of Pediatrics, ${ }^{5}$ the investigation of CVD risk factors in children and adolescents is recommended regardless of the nutritional condition, and its central point is the presence of a family history of early CVD (HCVD). ${ }^{5}$ According to this recommendation, children from 2 to 8 years of age with HCVD and all children aged from 9 to 11 years should have their lipid profile evaluated. The proposal for this evaluation is 
to use the dosage of non-HDL cholesterol (NHDL-c) as initial screening, establishing the complete lipid profile if NHDL-c values are equal to or greater than $145 \mathrm{mg} / \mathrm{dL}^{5}$

The search for risk factors for CVD in the clinical history of children is one of the goals that should be incorporated into pediatric care. However, the need for complement the investigation through subsidiary exams in healthy children is still not consolidated in literature.

The aim of this study was to describe the values of NHDL-c and frequency of HCVD in healthy and prepubescent children, in addition to checking possible associations between NHDL-c and HCVD with other CVD risk factors.

\section{Method}

By means of an anthropometric census conducted by the Division of General and Community Pediatrics, Pediatrics Department of the Federal University of São Paulo, in São Paulo, Brazil, 920 schools children were invited to participate in this cross-sectional study. We evaluated 766/920 (83.3\%) children aged 6 to 10 years, whose parents had signed an informed consent form. Among these children, 540/766 (70.5\%) presented a normal body mass index (BMI). Next, the children who already showed secondary sex characteristics and those who had not collected blood samples were excluded, totaling 269/540 (49.8\%) prepubescent schoolchildren (117 girls and 152 boys), between 6 and 10 years old with a normal BMI (1SD < BMI >-2 SD; World Health Organization, 2007). ${ }^{6}$

This study was approved by the Ethics Committee of the Institution (São Paulo, Brazil no. 1568/09) and, in order to participate, the parents/guardians of the children signed an informed consent form.

A pre-coded questionnaire was applied to the parents/ guardians of the children to obtain information on birth weight and prematurity, to search for pre-existing diseases and investigate family history for CVD (HCVD). ${ }^{5}$ A family history was considered to be present when the parents reported high blood pressure, diabetes, obesity or hypercholesterolemia. As the parents of these schoolchildren were perhaps too young to show evident coronary disease, we also considered a positive history the occurrence of myocardial infarction or sudden death in the grandparents before 55 years of age. Staging of puberty was performed by a pediatrician as per the recommendations of Tanner \& Marshall. ${ }^{7}$

Weight data was obtained on platform-type mechanical scales (SD-150, Country Technologies, Wisc, USA), graduated every $0.1 \mathrm{~kg}$, with the child using the least possible amount of clothing, without shoes, while height measurement was done on a vertical stadiometer graduated in millimeters $(1 \mathrm{~mm}) .{ }^{8}$ This data was used for classifica- tion of nutritional status using the indicators and cut-off points proposed by the World Health Organization, 2007. They were considered healthy if $1 \mathrm{SD}<\mathrm{BMI}>-2 \mathrm{SD}^{6}$

Waist circumference (WC) was measured with an inextensible tape measure at the midpoint between the upper iliac crest and the last fixed rib. Values higher than the 90 percentile according to sex and age were considered unsuitable. ${ }^{9}$ WC was also used to calculate the waist/ height ratio (cut-off point < 0.5). ${ }^{10}$

Blood pressure (SBP - systolic and DBP - diastolic) was measured using a sphygmomanometer by a single evaluator, and recorded from the average of three measurements, with five minutes intervals, in a single session. High blood pressure included values above the 90 percentile for gender, age and height. ${ }^{11}$

Blood collection: After 12 hours of fasting, $5 \mathrm{~mL}$ of blood were collected via peripheral venipuncture for determination of the lipid profile, blood glucose and insulin. The samples were centrifuged after one hour (1500 $\mathrm{rpm}$ for five minutes), aliquoted and used for determination of plasma concentrations of total cholesterol (TC), HDL-c, triglycerides (TG) (colorimetric method) and LDL$c$ (Friedewald equation). The cut-off points used were those proposed by the American Academy of Pediatrics, 2008. ${ }^{12}$ Based on the lipid profile we calculated the non-HDL cholesterol (TC - HDL-c; cut-off point $<145 \mathrm{mg} / \mathrm{dL}$ ). ${ }^{13}$ Blood concentrations of glucose (colorimetric method) and insulin (chemiluminescence) were used for the evaluation of insulin resistance under the homeostatic model assessment calculation (HOMA-IR; glucose $(\mathrm{mg} / \mathrm{dL}) / 18 \mathrm{x}$ insu$\operatorname{lin}(\mathrm{mIU} / \mathrm{mL})] / 22.5)$. The cut-off point for blood glucose was $<100 \mathrm{mg} / \mathrm{dL}$ and HOMA-IR $<2.0 .{ }^{14}$

The data collected was typed and consolidated in an Excel $^{\circledR}$ spreadsheet. SPSS 20.0 (IBM) statistics software was used for analysis. The continuous variables were tested as to their normality through using Shapiro-Wilk test, and Student's t-test for parametric variables and the Mann-Whitney $U$ test for nonparametric variables. Categorical variables were compared using chi-squared test or Fisher's exact test. Cramer's V test was used to evaluate the association between HCVD and NHDL-c. For the multivariate analysis we used the Forward LR logistic regression method and included those with $\mathrm{p}<0.1$ in the bivariate analysis. A significance level of 5\% was adopted.

\section{Results}

Among the children evaluated, 58.7\% were boys and the median age was 8.3 years $(6.0 ; 10.9)$. The frequency of changes in the variables studied can be observed in Table 1. A high percentage of unsuitability was found in relation to the lip- 
id profile, especially for triglycerides: 92 (34.2\%) and HDLc: 91 (33.8\%). No children included in the study had an increased waist circumference or waist/height ratio above 0.5 .

TABLE 1 Frequency of clinical and laboratorial changes as variables studied in healthy and prepubescent

\section{schoolchildren.}

\begin{tabular}{|c|c|c|c|}
\hline \multicolumn{2}{|l|}{ Variable } & \multicolumn{2}{|c|}{ Total $(n=269)$} \\
\hline Birth weight & $<2500 \mathrm{~g}$ & $35(13 \%)$ & \\
\hline Family HCVD & Present & $46(17.1 \%)$ & \\
\hline Systolic BP & $\geq p 90$ & $3(1.1 \%)$ & \\
\hline Diastolic BP & $\geq \mathrm{p} 90$ & $12(4.5 \%)$ & \\
\hline HOMA-IR & $>2.0$ & $50(23.9 \%)$ & \\
\hline \multirow[t]{2}{*}{ Blood glucose } & $\geq 100 \mathrm{mg} / \mathrm{dL}$ & $4(1.4 \%)$ & \\
\hline & & Borderline & High \\
\hline Triglycerides & $75-99$ and $\geq 100$ & $65(24.2 \%)$ & $36(13.3 \%)$ \\
\hline TC & $170-199$ and $\geq 200$ & $60(22.3 \%)$ & $5(1.8 \%)$ \\
\hline HDL-c & $<40$ and $\geq 45$ & $71(26.4 \%)$ & $24(8.9 \%)$ \\
\hline LDL-c & $100-129$ and $\geq 130$ & $35(13.0 \%)$ & $7(2.6 \%)$ \\
\hline NHDL-c & $120-145$ and $\geq 145$ & $52(19.3 \%)$ & $10(3.7 \%)$ \\
\hline
\end{tabular}

The median of the values for NHDL-c was $102.0 \mathrm{mg} / \mathrm{dL}$ $(47.0 ; 187.0)$, with no statistically significant difference between genders (data not shown).

In the population studied, high NHDL-c was found in $10(3.7 \%)$ children, and HCDV was found in 46 (17.1\%). A weak association was found between family HCVD and NHDL-c (Cramer's V test $=0.120 ; \mathrm{p}=0.050)$. Among children with NHDL-c $\geq 145 \mathrm{mg} / \mathrm{dL}, 4$ (40\%) had a family history of CDV.
The presence of HCDV was not associated in a statistically significant manner with the variables studied (Table 2). Although there was no difference, the group of children with HCVD had higher median values of NHDL-c compared to the schoolchildren without HCVD (Table 2).

The variables that were independently associated with NHDL-c were HOMA-IR and PAD (Table 3). The increase of one unit in HOMA-IR and PAD was associated with $\mathrm{OR}=1.7(95 \% \mathrm{CI} 1.1-2.6)$ and $\mathrm{OR}=1.1(1.02-1.02)$ for unsuitability of NHDL-c, respectively.

\section{Discussion}

In this study of healthy and prepubescent schoolchildren, risk factors for CVD were found, both clinically and connected to the metabolic and lipid profile of this population. Among the predictors analyzed (family HCVD and NHDL-c), NHDL-c values above $145 \mathrm{mg} / \mathrm{dL}$ were associated with a greater number of factors related to the development of CVD (DBP and HOMA-IR) than family history alone. Furthermore, a weak association was noted between HCVD and increased NHDL-c.

The investigation of HCVD in the pediatric age range has been debated intensively in recent years in view of the increase in morbidity and mortality caused by CVD in the general population. ${ }^{5}$ Obesity and associated morbidities are well-known and widely investigated risk factors. ${ }^{3,4}$ Nevertheless, there are few studies addressing HCVD in healthy children. Currently, there is no consensus about who, when and how to investigate HCVD in this group.

In a recent publication on guidelines for the reduction of cardiovascular risk in children, the authors suggest that family HCVD is the central item to defining the need to

TABLE 2 Comparison of the variables studied in children for the presence of family history of cardiovascular disease.

\begin{tabular}{|c|c|c|c|c|}
\hline Variable & & $\begin{array}{l}\text { HCVD }(+) \\
(n=46)\end{array}$ & $\begin{array}{l}\operatorname{HCVD}(-) \\
(n=223)\end{array}$ & p-value \\
\hline Age & years & $8.6(6.1 ; 10.9)$ & $8.3(6.0 ; 10.9)$ & $0.225^{*}$ \\
\hline Birth weight & grams & $3020(1250 ; 4400)$ & $3180(875 ; 4830)$ & $0.243^{*}$ \\
\hline BMI & $z$-score & $0.06(-1.7 ; 0.9)$ & $-0.23(-1.9 ; 0.9)$ & $0.248^{*}$ \\
\hline Waist/height & $\mathrm{cm}$ & $0.42(0.4 ; 0.5)$ & $0.42(0.2 ; 0.5)$ & $0.569^{*}$ \\
\hline Systolic BP & $\mathrm{mmHg}$ & $90.0(80.0 ; 110.0)$ & $90.0(70.0 ; 120.0)$ & $0.213^{*}$ \\
\hline Diastolic BP & $\mathrm{mmHg}$ & $60.0(40.0 ; 80.0)$ & $60.0(40.0 ; 80.0)$ & $0.173 *$ \\
\hline HOMA-IR & & $1.2(0.3 ; 6.7)$ & $1.0(0.1 ; 7.0)$ & $0.356^{*}$ \\
\hline Blood glucose & $\mathrm{mg} / \mathrm{dL}$ & $81.0(69.0 ; 103.0)$ & $80.0(46.0 ; 107.0)$ & $0.064^{*}$ \\
\hline Insulin & $\mathrm{uU} / \mathrm{mL}$ & $6.3(1.4 ; 31.0)$ & $5.6(1.0 ; 31.8)$ & $0.446^{*}$ \\
\hline NHDL-c & $\mathrm{mg} / \mathrm{dL}$ & $109.5(61.0 ; 187.0)$ & $101.0(47.0 ; 161.0)$ & $0.060 *$ \\
\hline Gender & male & 24 & 128 & $0.519 \dagger$ \\
\hline
\end{tabular}


TABLE 3 Comparison of the variables studied in children regarding concentrations of non-HDL cholesterol (NHDL-c).

\begin{tabular}{|c|c|c|c|c|}
\hline Variable & & $\begin{array}{l}\text { NHDL-c } \geq 145 \mathrm{mg} / \mathrm{dL} \\
(\mathrm{n}=10)\end{array}$ & $\begin{array}{l}\text { NHDL-c <145 mg/dL } \\
(n=259)\end{array}$ & $\mathrm{p}$-value \\
\hline Age & years & $9.3(6.0 ; 10.0)$ & $8.3(5.0 ; 10.0)$ & $0.185^{*}$ \\
\hline Birth weight & grams & $2820(2080 ; 3878)$ & $3180(875 ; 4830)$ & $0.300^{*}$ \\
\hline $\mathrm{BMI}$ & $z$-score & $0.20(-1.5 ; 0.8)$ & $-0.15(-1.9 ; 0.9)$ & $0.647^{*}$ \\
\hline Waist/height & $\mathrm{cm}$ & $0.43(0.4 ; 0.5)$ & $0.42(0.2 ; 0.5)$ & $0.213^{*}$ \\
\hline Systolic BP & $\mathrm{mmHg}$ & $92.5(80.0 ; 100.0)$ & $90.0(70.0 ; 120.0)$ & $0.063 *$ \\
\hline Diastolic BP & $\mathrm{mmHg}$ & $65.0(50.0 ; 80.0)$ & $60.0(40.0 ; 80.0)$ & $0.008^{*}$ \\
\hline HOMA-IR & & $2.2(1.3 ; 7.0)$ & $1.05(0.1 ; 6.6)$ & $<0.001^{*}$ \\
\hline Blood glucose & $\mathrm{mg} / \mathrm{dL}$ & $85.5(70.0 ; 95.0)$ & $80.0(46.0 ; 107.0)$ & $0.103^{*}$ \\
\hline Insulin & $\mathrm{IU} / \mathrm{mL}$ & $9.9(6.6 ; 31.8)$ & $5.5(1.0 ; 31.0)$ & $<0.001^{*}$ \\
\hline Gender & male & $6(60 \%)$ & $146(56.3 \%)$ & $0.544^{\dagger}$ \\
\hline Cardiovascular risk & present & $4(40 \%)$ & $42(16.2 \%)$ & $0.073^{\dagger}$ \\
\hline
\end{tabular}

widen the investigation of CVD risk in healthy children or not. ${ }^{5}$ In practice, despite being simple to collect, the interpretation of this data in the scope of clinical history has certain obstacles. The report about the family is sometimes unnecessary. The most robust evidence relates to first-degree relatives (parents) who are often too young to have more serious cardiovascular outcomes. ${ }^{3,5}$ Much of the young adult population has not yet adopted routine lipid profiling, which is one of the factors evaluated in family HDCV. In the general population, there is a high prevalence of dyslipidemia, hypertension and diabetes related to obesity and lifestyle, which makes the differentiation of environmental and genetic factors difficult. ${ }^{15}$

In our study, we found that family HCVD was not associated with other classical risk factors for CVD, although the frequency found was almost five times higher for high NHDL-c and the median values of NHDL-c tend to be higher in the group with family HCVD. These findings are consistent with those observed in a large population study (Coronary Artery Risk Detection in Appalachian Communities - CARDIAC project) where the authors found that family history failed to identify dyslipidemia (LDL-c $>130 \mathrm{mg} / \mathrm{dL}$ ) in healthy subjects. ${ }^{16}$

According to the American Academy of Pediatrics, ${ }^{5}$ universal screening for dyslipidemia is recommended in children aged 9 to 11 years based on determination of the lipid profile without the need of fasting and the calculation of the NHDL-c. If these values are above $145 \mathrm{mg} / \mathrm{dL}$, another lipid profile should be requested within two weeks (total cholesterol and fractions) under 12-hour fasting and with individual analysis of the fractions. This universal investigation can also be conducted in children aged 2 to 9 years if there is family HCVD and avoided in children younger than 2 years for there are no established cut-off points, as well as in adolescents, considering that there is a physiological decrease in concentrations of lipoproteins, especially LDL-c, during puberty. ${ }^{5}$

NHDL-c has been presented in recent publications as the best predictor of CVD in the long-term compared with other components of the lipid profile, such as total cholesterol, LDL-c and the LDL/HDL ratio. A cohort study (Bogalusa Heart Study) noted that the NHDL-c values in childhood are more strongly associated with the thickness of the intima-media complex of the carotid in young adults. ${ }^{17}$

The calculation of NHDL-c is simple and fasting is not required for its evaluation. NHDL-c measures the atherogenic particles that contain the apolipoprotein (LDL-c, small and dense particles, VLDL-c, chylomicron remnants, IDL-c). ${ }^{18}$ In our study, NHDL-c values $\geq 145$ $\mathrm{mg} / \mathrm{dL}$ were independently associated with diastolic blood pressure and insulin resistance as measured by HOMAIR. These findings are similar to those seen in the publication of the group from the Bogalusa Heart Study. ${ }^{12}$ Also, NHDL-c can be considered a predictor of type 2 diabetes mellitus. ${ }^{19}$

A recent American population study found the average and percentage of unsuitability of NHDL-c at 110 $\mathrm{mg} / \mathrm{dL}$ and $11.8 \%$, respectively, in the age range between 9 and 11 years. ${ }^{13}$ These results are higher than those described in our study, which were $102 \mathrm{mg} / \mathrm{dL}$ and $3.7 \%$.

Despite this set of findings, universal screening based on NHDL-c is not yet a consensus. Critics suggest that it is based on weak evidence, that there are no cost-benefit 
studies in the short and long term, that this investigation may lead to greater anxiety in the family, increased adoption of restrictive diets and the use of lipid-lowering medication at pediatric age. ${ }^{20}$

In our study, only 10 (3.7\%) of the children would require another blood collection for determination of the lipid profile, according to the recommendation for universal screening. On the other hand, if we were to use the family HCVD alone, this figure would be five times higher. The study model does not allow us to define what would be better in the study of CVD risk in this population. However, it is clear that this topic needs to be further explored and discussed, in order to define the best practice for the pediatric routine in view of the high prevalence of CVD in our population.

A greater number of schoolchildren participating in the study could statistically confirm the trend observed between the higher systolic BP in the group with high NHDL-c and the higher NHDL-c levels in the group with family HCVD. Another limitation refers to not having used more accurate methods to assess the risk of CVD, such as intima-media thickness.

\section{Conclusion}

This study demonstrated NHDL-c values associated with CVD risk factors such as blood pressure and insulin resistance. Family HCVD was not associated with classical risk factors for CVD, although the frequency of positive HCVD found was almost five times higher than that of high NHDL-c. The identification of early HCVD in children should be part of the pediatric routine, regardless of nutritional status, and a healthy lifestyle should be proposed and encouraged for both the child and the family.

\section{Resumo}

Importância clínica da história familiar de doença cardiovascular e da dosagem do colesterol não HDL em crianças eutróficas

Objetivos: descrever os valores do colesterol não HDL (NHDL-c) e a frequência de história cardiovascular familiar precoce (HDCV familiar) em crianças eutróficas e pré-púberes. Analisar a associação entre o NHDL-c e o HDCV familiar e possíveis associações com outros fatores de risco para doenças cardiovasculares (DCV).

Método: estudo transversal com 269 escolares (6-10 anos) pré-púberes e com índice de massa corporal normal (+1DP<IMC>-2DP). Dados coletados: HDCV familiar; peso e estatura, circunferência abdominal e pressão arte- rial sistêmica; perfil lipídico (colesterol total - CT, HDL-c, triglicérides e LDL-c), cálculo do NHDL-c (CT-HDL-c, ponto de corte $145 \mathrm{mg} / \mathrm{dL}$ ) e resistência à insulina (HOMA-IR).

Resultados: observaram-se valores elevados de NHDL-c em $10(3,7 \%)$ e presença de HDCV familiar precoce em 46 $(17,1 \%)$ crianças. Houve fraca associação entre HDCV familiar e NHDL-c (Cramer's-V-test $=0,120 ; p=0,050)$. Entre as crianças com NHDL-c $\geq 145 \mathrm{mg} / \mathrm{dL}$, quatro (40\%) tinham HDCV familiar. A presença de HDCV familiar não se associou com as variáveis estudadas. As variáveis que se associaram de forma independente com o NHDL-c $\geq 145 \mathrm{mg} / \mathrm{dL}$ foram HOMA-IR (OR=1,7; IC95\% 1,1-2,6) e pressão arterial diastólica (OR=1,1; IC95\% 1,02-1,2).

Conclusão: os valores de NHDL-c se associaram com pressão arterial e resistência insulínica. HDCV familiar não se associou com outros fatores de risco clássicos para $\mathrm{DCV}$, embora a frequência encontrada tenha sido quase cinco vezes superior à de NHDL-c elevado.

Palavras-chave: dislipidemias, doenças cardiovasculares, criança, prevenção primária.

\section{References}

1. Mendis S, Puska P, Norrving B (eds.). Global atlas on cardiovascular disease prevention and control. Geneva: World Health Organization, 2011.

2. Ministério do Planejamento, Orçamento e Gestão. Instituto Brasileiro de Geografia e Estatística (IBGE). Indicadores Sociodemográficos de Saúde no Brasil. Rio de Janeiro, 2009. 152p.

3. Berenson GS, Srinivasan SR, Bao W, Newman WP 3rd, Tracy RE, Wattigney WA. Association between multiple cardiovascular risk factors and atherosclerosis in children and young adults. The Bogalusa Heart Study. N Engl J Med. 1998; 338(23):1650-6.

4. Power C, Pinto Pereira SM, Law C, Ki M. Obesity and risk factors for cardiovascular disease and type 2 diabetes: Investigating the role of physical activity and sedentary behaviour in mid-life in the 1958 British cohort. Atherosclerosis. 2014; 233(2):363-9.

5. American Academy of Pediatrics. Expert panel on integrated guidelines for cardiovascular health and risk reduction in children and adolescents summary report. Pediatrics. 2011; 128(Suppl 5):S213-56.

6. de Onis M, Onyango AW, Borghi E, Siyam A, Nishida C, Siekmann J. Development of a WHO growth reference for school-aged children and adolescents. Bull World Health Organ. 2007; 85(9):660-7.

7. Marshall WA, Tanner JM. Variations in pattern of pubertal changes in girls and boys. Arch Dis Child. 1969; 44(235):291-303.

8. WHO Expert Committee on Physical Status: the use and interpretation of anthropometry: report of a WHO expert committee. WHO technical report series; 854. Geneva: WHO, 1995. p.452.

9. Freedman DS, Serdula MK, Srinivasan SR, Berenson GS. Relation of circumferences and skinfold thicknesses to lipid and insulin concentrations in children and adolescents: The Bogalusa Heart Study. Am J Clin Nutr. 1999; 69(2):308-17.

10. Kuba VM, Leone C, Damiani D. Is waist-to-height ratio a useful indicator of cardio-metabolic risk in 6-10-year-old children? BMC Pediatr. 2013; 13:91.

11. National High Blood Pressure Education Program Working Group on High Blood Pressure in Children and Adolescents. The fourth report on the diagnosis, evaluation, and treatment of high blood pressure in children and adolescents. Pediatrics. 2004; 114(Suppl 2):555-76.

12. Daniels SR, Greer FR; Committee on Nutrition. Lipid screening and cardiovascular health in childhood. Pediatrics. 2008; 122(1):198-208. 
13. Dai S, Yang Q, Yuan K, Loustalot F, Fang J, Daniels SR, et al. Non-highdensity lipoprotein cholesterol: distribution and prevalence of high serum levels in children and adolescents: United States national health and nutrition examination surveys, 2005-2010. J Pediatr. 2014; 164(2):247-53.

14. Peters A, Laffel L; American Diabetes Association Transitions Working Group. Diabetes care for emerging adults: recommendations for transition from pediatric to adult diabetes care systems. Diabetes Care. 2011; 34(11):2477-85

15. Ogden CL, Carroll MD, Curtin LR, Lamb MM, Flegal KM. Prevalence of high body mass index in US children and adolescents, 2007-2008. JAMA. 2010; 303(3):242-9.

16. Ritchie SK, Murphy EC, Ice C, Cottrell LA, Minor V, Elliott E, et al. Universal versus targeted blood cholesterol screening among youth: The CARDIAC Project. Pediatrics. 2010; 126(2):260-5.
17. Frontini MG, Srinivasan SR, Xu J, Tang R, Bond MG, Berenson GS. Usefulness of childhood non-high density lipoprotein cholesterol levels versus other lipoprotein measures in predicting adult subclinical atherosclerosis: the Bogalusa Heart Study. Pediatrics. 2008; 121(5):924-9.

18. Dai S, Yang Q, Yuan K, Loustalot F, Fang J, Daniels SR, et al. Non-highdensity lipoprotein cholesterol: distribution and prevalence of high serum levels in children and adolescents: United States National Health and Nutrition Examination Surveys, 2005-2010. J Pediatr. 2014; 164(2):247-53.

19. Ley SH, Harris SB, Connelly PW, Mamakeesick M, Gittelsohn J, Wolever TM, et al. Utility of non-high-density lipoprotein cholesterol in assessing incident type 2 diabetes risk. Diabetes Obes Metab. 2012; 14(9):821-5.

20. Sniderman A, Kwiterovich PO. Update on the detection and treatment of atherogenic low-density lipoproteins. Curr Opin Endocrinol Diabetes Obes. $2013 ; 20(2): 140-7$. 